\title{
CHARACTERISTICS OF VIM/VAR-PROCESSED ALLOY 718 INGOT AND THE EVOLUTION OF MICROSTRUCTURE DURING COGGING
}

\author{
N.-K. Park ${ }^{1}$, J.-T. Yeom ${ }^{1}$, J. -H. Kim ${ }^{1}$, X.-X. Cui ${ }^{1}$ \\ ${ }^{1}$ Materials Processing Research Center, Korea Institute of Machinery \& Materials \\ 66 Sangnamdong, Changwon, Gyeongnam 641-010, Rep. of Korea
}

Keywords: Alloy718, VAR, Ingot, Billet Cogging

\begin{abstract}
Alloy 718 ingot with a diameter of $300 \mathrm{~mm}$ was made by the vacuum melting process; VIM (vacuum induction melting) followed by VAR (vacuum arc re-melting). The VIM/VAR ingot was heat-treated for homogenization, and casting structure of the ingot was broken down for uniform microstructures and mechanical properties by controlled cogging processes using a hydraulic press.

The VIM/VAR-processed ingot contains three different microstructure zones along radial direction, i.e. surface chill zone, intermediate columnar gain zone, and central equiaxed zone, because the local solidification procedure varies depending on locations within the ingot. To understand the local deformation behavior and microstructure evolution, compression tests were conducted on samples collected from different zones of the ingot in wide temperature and strain rate ranges, i.e. $900 \sim 1150{ }^{\circ} \mathrm{C}$ and $0.01 \mathrm{~s}^{-1}$. The existence of different microstructures within the ingot resulted in different compression behaviors, which was attributed to the preferred orientation in the columnar grain zone, in comparison with the equiaxed grains in the central region. At large strains, the initial difference in microstructure eventually disappeared due to dynamic, meta-dynamic, and static recrystallizations. Constitutive relations were established for the simulation of microstructure evolution, which was applied to the billet cogging process.
\end{abstract}

\section{Introduction}

Large diameter ingots of a nickel base Alloy 718 are normally made by vacuum melting processes, i.e., VIM (vacuum induction melting) followed by VAR (vacuum arc re-melting) or ESR (electro-slag re-melting) in double melting processes, or by the combination of ESR and VAR in triple melting processes. Even though VIM/VAR- or VIM/ESR-processed ingots contain relatively uniform microstructures and alloy chemistry when compared to the as-VIM processed ingot, there remain some undesired casting structures in the order of tens of microns, including Laves phase, carbides, etc. The casting structures can be broken down by appropriate cogging processes for homogeneous chemistry and microstructures, and sound mechanical properties [1]. Grain size is a typical way of controlling mechanical properties of Alloy 718, i.e., coarser grain size is favored for creep strength and crack-growth resistance, and finer-grain structure for lowcycle fatigue life and tensile yield strength. The grain size can be controlled by dynamic recrystallization, meta-dynamic recrystallization, static recrystallization, and grain growth. The grain size of the billet varies depending on locations within the billet, which is often observed in actual billet making processes. The difference in grain size greater than ASTM \#2 is frequent in large diameter billets. The difference in the grain size within the billet may be induced by the differences in the ingot quality, i.e. chemistry and grain structure, and by the differences in billet conditions, i.e. temperature, strain rate, strain, etc.[2] The process parameters for billet cogging 
can be defined by the state variables, including strain, strain rate, and temperature. The feed rate and upset ratio in billet cogging are important to ensure the soundness of the billet.

The aim of this research is to investigate the local inhomogeneities in the microstructure of Alloy 718 ingot, and their potential effects on cogging. The microstructure of VIM/VAR processed ingot was carefully characterized, and the cogging process was evaluated in an effort to achieve a uniform microstructure in the final billet. The effects of inhomogeneous microstructures in VIM/VAR-processed billet on the flow behavior and microstructure evolution are discussed for the simulation of press forging. The template of Deform 3D was used for cogging analysis. Decoupled FE simulation method, using numerous steps for cogging process to calculate accumulated state variables, was employed for the study of recrystallizations and grain growth within the billet.

\section{Characteristics of the Ingot Structure}

A VIM/VAR-processed Alloy 718 ingot with a diameter of $300 \mathrm{~mm}$ was investigated in this study. The chemical compositions of the alloy are presented in Table 1. The VIM/VARprocessed ingot contains three microstructural features on its cross-section. The ingot is composed of outermost chill zone, intermediate columnar grain zone, and central equiaxed zone. And, it is found that the thickness of each zone varies with the local solidification procedure. Fig. 1 shows that the difference in microstructure can be attributed to the difference in overall solidification process that varies with locations within the ingot. Due to the heat loss from the ingot to the lower bottom part and also from the ingot to the outer copper crucible, the grains grew in a concave way from the bottom to the top and from the surface to the center of the ingot. The details of dendritic structure also vary from the center to the surface, and from the bottom to the top of the ingot.

For the study of microstructures of the ingot and billet, the outermost surface, top and bottom parts of the ingot were discarded before cogging. The center part of the ingot consists of coarser microstructure than those of the columnar region, and the dendrite arm spacing of the center part is thicker than that of the columnar region as shown in Fig. 2. It is here to be noted that the macrosegregation was negligible regardless of the size of the local microstructure. The amount of $\mathrm{Nb}$, which is most prone to segregation, may vary depending on ingot size from $2 \mathrm{wt} \%$ in the dendrite arms to $10 \mathrm{wt} \%$ in the interdendritic regions for Alloy 718 ingots [3]. Accordingly, an extensive Laves phase as well as carbides is precipitated in the interdendritic regions. The Laves phase is represented as $\mathrm{A}_{2} \mathrm{~B}$, where ' $\mathrm{A}$ ' atoms are primarily $\mathrm{Ni}, \mathrm{Fe}$, and $\mathrm{Cr}$, and the ' $\mathrm{B}$ ' atoms are $\mathrm{Nb}, \mathrm{Mo}$, and Ti. [4].

Table 1. Chemical compositions of Alloy 718 used in this study.

\begin{tabular}{|c|c|c|c|c|c|c|c|c|c|c|c|c|c|c|}
\hline & $\mathrm{C}$ & $\mathrm{P}$ & $\mathrm{S}$ & $\mathrm{Mn}$ & $\mathrm{Si}$ & $\mathrm{Cr}$ & $\mathrm{Mo}$ & $\mathrm{Co}$ & $\mathrm{Ti}$ & $\mathrm{Al}$ & $\mathrm{B}$ & $\mathrm{Fe}$ & $\mathrm{Zr}$ & $\mathrm{Ni}$ \\
\hline comp. & .046 & .006 & .002 & .06 & .10 & 19.2 & 2.8 & .22 & 1.1 & .62 & .04 & 17.7 & .05 & Bal. \\
\hline
\end{tabular}

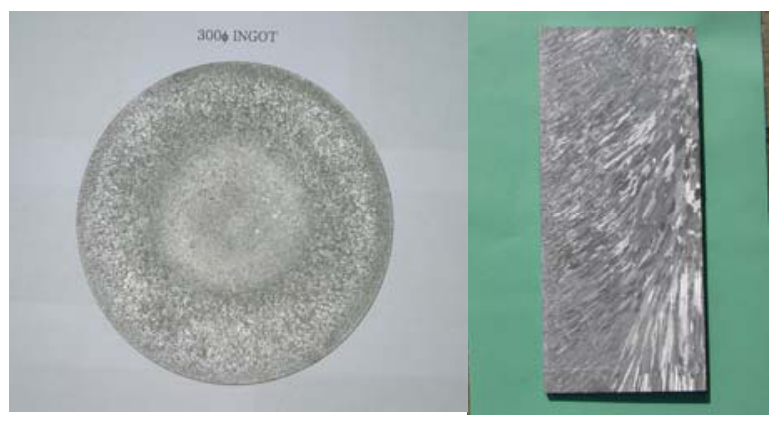

(a) Cross section

(b) Vertical section

Fig. 1 Macrostructure of VIM/VAR-processed ingot 


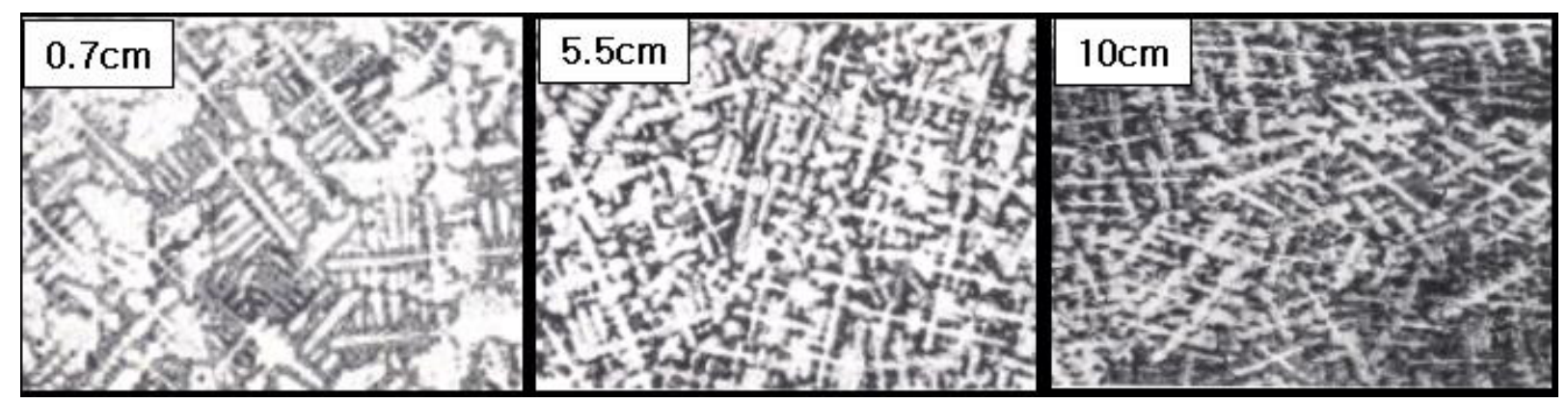

Fig. 2. Center-to-surface distribution of dendritic structure of the VIM/VAR-processed ingot.

A homogenization treatment at $1150{ }^{\circ} \mathrm{C}$ was employed to remove the micro-segregation of the VIM/VAR-processed ingot, and to dissolve the Laves phase formed in VAR process. Dendritic microstructure disappeared and alloy chemistry became uniform following the homogenization treatment. In addition, grain size was increased somewhat, due to the dissolution of the Laves phase and carbides.

$\mathrm{X}-\mathrm{RD}$ analysis was made in order to understand the microstructure of columnar grain zone and central equiaxed grain zone. The central equiaxed grain zone showed a random orientation relationship, but columnar grain zone showed a strong preferred index, which will be discussed later. The different local solidification process resulted in the change in microstructure and mechanical properties of the billet. The variation of preferred orientations in columnar grain zone was assessed during high temperature compression tests.

\section{Flow Behavior of the Ingot under Compression}

It is expected that the locally different microstructures of the ingot show different mechanical behavior in the cogging process. It is conjectured from Fig. 1 that the flow stress levels of columnar grain zone would be different from those of the central equiaxed grain zone. To investigate the local mechanical behavior, compression tests were conducted on the samples that were machined from the center region and also from the columnar region of the ingot. All the compression test samples were made in parallel to the length direction of the ingot. A Thermecmaster testing machine was used for compression tests, and the specimens were heated to the test temperature at the heating rate of $50{ }^{\circ} \mathrm{C} / \mathrm{s}$, and held at each temperature for $5 \mathrm{~min}$. to ensure temperature uniformity. Compression tests were conducted in wide temperature and strain rate ranges, i.e. $900 \sim 1150{ }^{\circ} \mathrm{C}$ and $0.01 \sim 10 \mathrm{~s}^{-1}$, respectively, and all the samples were gasquenched after each testing.

The present presumption that a preferred orientation would result in a different deformation behavior can be confirmed by the shape change in compression-tested samples, as shown in Fig. 3. Compression-tested specimens obtained from the columnar grain zone, showed a square crosssection with measurable anisotropy. Fig. 4 also shows stress-strain curves of various samples obtained from different sections within the ingot. It is noted that the flow stress of columnar microstructure is generally higher than that of equiaxed one at relatively low strain level ( $\varepsilon \leq \sim 0.3)$. This fact indicates that the grains in the columnar grain zone have 'hard' orientations compared to those of the equiaxed grain zone.

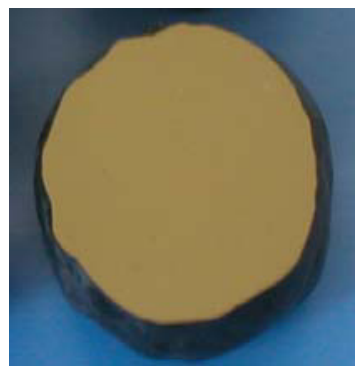

(a)

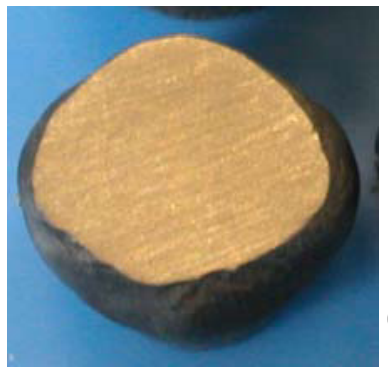

(b)

Fig. 3. Deformation anisotropy formed in compression specimens obtained from (a) equiaxed grain zone, (b) columnar grain zone. 

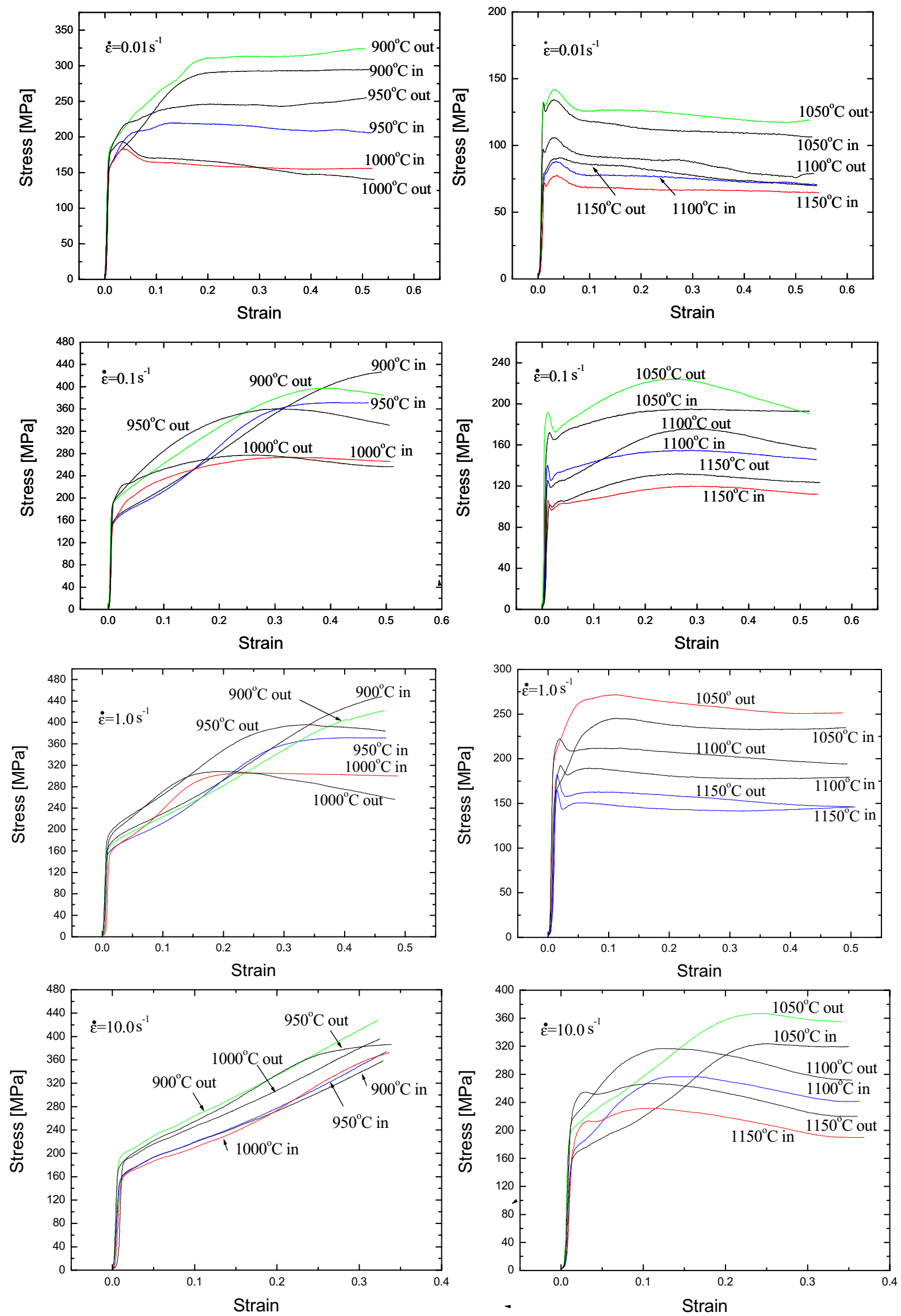

Fig. 4. Effects of specimen locations on the flow behavior in compression tests. 


\section{Evolution of Microstructure during Deformation}

Recrystallized grains start to form preferentially at grain boundaries, as well as at some carbides or carbonitride particles. Near the surface, where the temperature is low due to die chilling and radiation cooling, only a small fraction of recrystallization takes place. When the microstructure is reheated at sufficiently high temperatures, i.e. above $1050{ }^{\circ} \mathrm{C}$, recrystallization and grain growth take place. As such, a fully recrystallized structure can be produced by repeated deformation and reheating.

It is worth noting that the preferred orientation observed in the columnar grain zone decreases with the deformation at high temperatures, due to the formation of randomly oriented grains. It is expected that the heavy deformation eventually reduces the initial orientation difference in the ingot microstructure and forms a homogeneous microstructure after the cogging process. As for validation tests, compression specimens were cut and tested in parallel to the three different axes of the ingot. Flow stress curves are presented in Fig. 5. It is clear that the difference in initial flow stress level decreases with increasing strain when the compression tests are conducted at $1100{ }^{\circ} \mathrm{C}$, indicating dynamic recystallization occurs actively during deformation. The amount of deformation needs to be large enough to produce a uniform microstructure, without forming a duplex structure consisting of coarse and unrecrystallized grains together with fine recrystallized grains formed near initial grain boundaries.
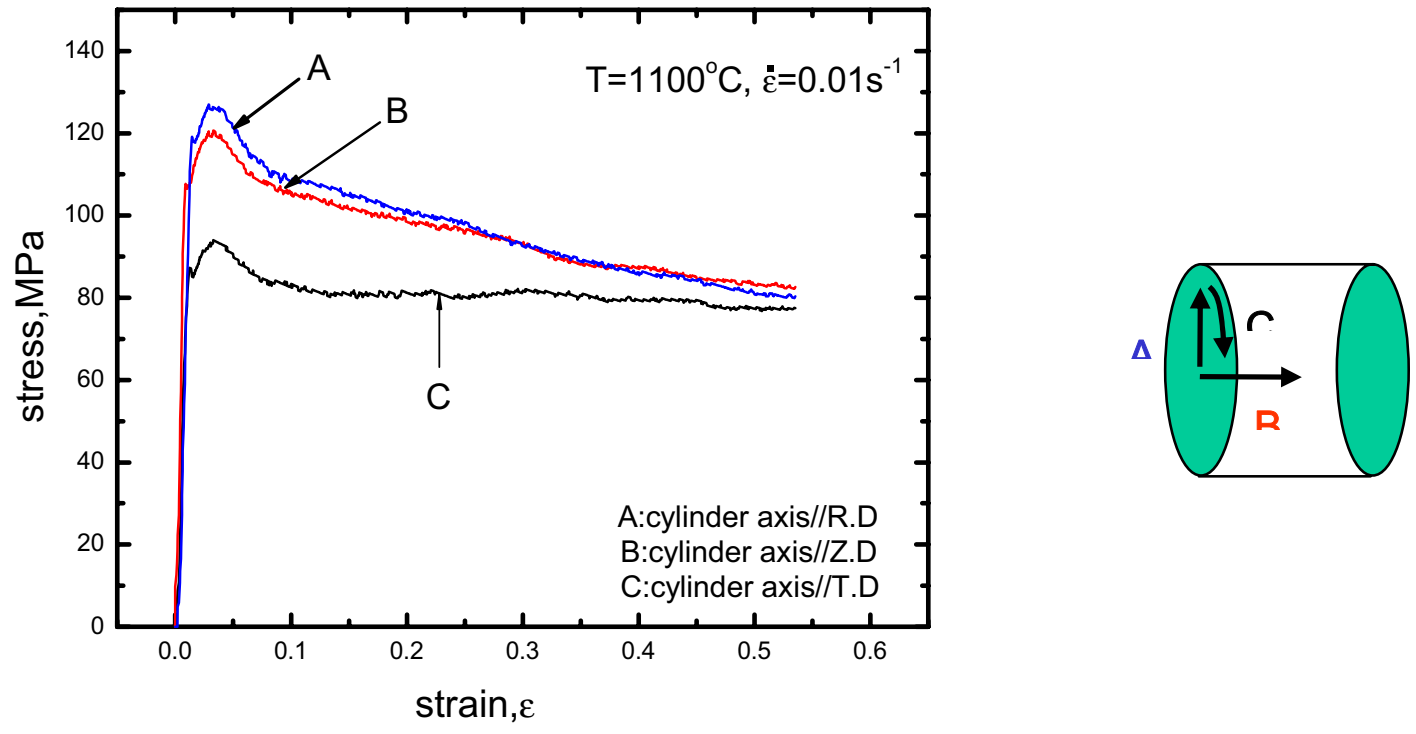

Fig. 5. Variation of flow stresses with compression axis and strain.

The existence of preferred orientations in the ingot can be seen in Fig. 6. The X-ray diffraction patterns are obtained from three different axes of the ingot; i.e. (a) indicates the X-ray pattern when the X-ray incidence plane is perpendicular to the radial direction of the ingot, (b) the X-ray pattern when the X-ray incident plane is perpendicular to the tangential direction of the ingot, and (c) the X-ray pattern when the X-ray incident plane is perpendicular to the longitudinal direction of the ingot. It is clear that the initial difference in the flow stress shown in Fig. 5 is attributed to the difference in preferred orientation of the samples. Fig. 7 shows that the relative intensity of $\{200\}$ plane in the columnar grains becomes stronger with strain, and X-ray patterns eventually show the randomly oriented structure pattern. Both the gradual decrease in flow stress and the loss of the preferred orientation with strain indicate that dynamic recrystallization is prominent when the compression tests are conducted at $1100{ }^{\circ} \mathrm{C}$ and $0.01 \mathrm{~s}^{-1}$. 


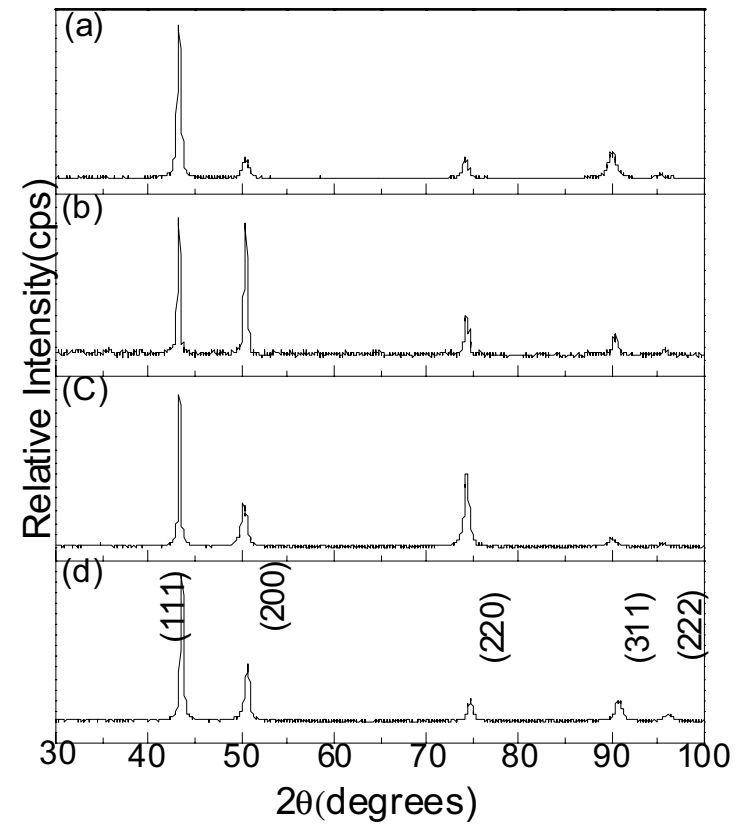

Fig. 6. XRD patterns obtained before compression tests.

(a) X-ray incidence plane $\perp$ R.D,

(b) X-ray incidence plane $\perp$ T.D,

(c) X-ray incidence plane $\perp$ Z.D

(d) Standard sample

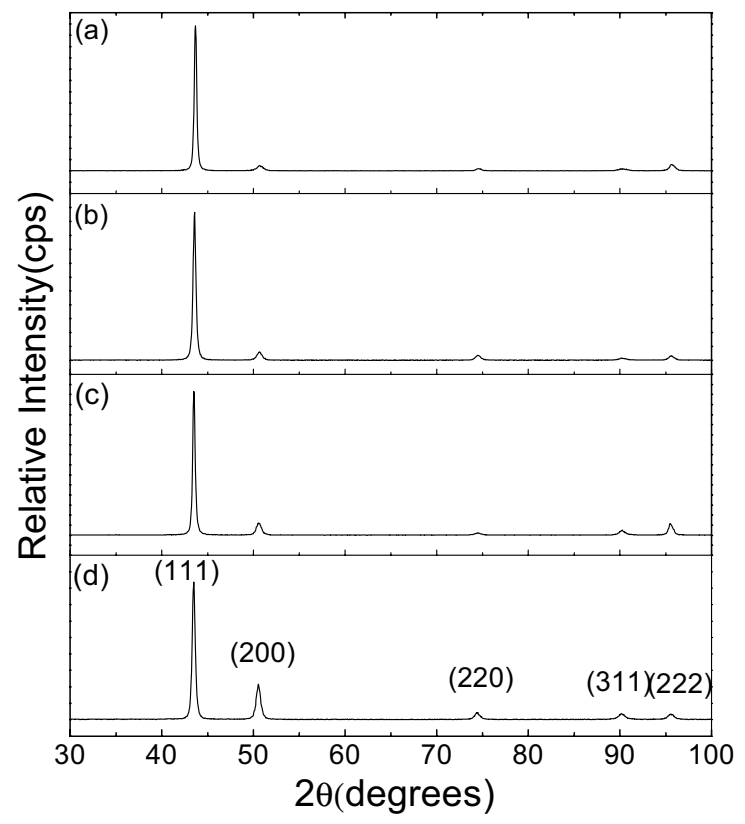

Fig. 7. Change in X-ray diffraction pattern with strains when testes at $1100{ }^{\circ} \mathrm{C}$ and $0.01 \mathrm{~s}^{-1}$ :

(a) 0.13 , (b) 0.39 , (c) 0.55 , (d) 0.73 .

\section{Simulation of Grain Structure under Side Pressing}

For the precise control of grain size, constitutive equations for the evolution of grain structure are established under normal cogging conditions. The constitutive model for grain structure covers dynamic recrystallization, meta-dynamic recrystallization, static recrystallization, and grain growth. $[5,6]$ The decoupled FE simulation, which considers accumulated state parameters during deformation, is previously shown to be appropriate for the prediction of microstructure of Alloy 718 [7]. The process parameters were carefully selected to represent the actual cogging process. With constitutive equations for the grain structure evolution, the evolution of microstructure of the billet can be simulated precisely.

Fig. 8 shows a conceptual procedure for the microstructure simulation of the billet. Deform-3D with a user-subroutine was employed for the analysis of grain structure. Local grain size was evaluated using constitutive equations based on experimental compression tests. The microstructure evolution was simulated for the side pressing of columnar grain sections of the ingot. Sections with a diameter of $50 \mathrm{~mm}$ were machined from the columnar grain zone, and were hot forged at the simulation condition. Fig. 9 shows the comparison of simulated results and experimental results, which has been carried out at the temperature of $1100^{\circ} \mathrm{C}$ with the height reduction of $50 \%$. Predicted grain size in the center region was below $60 \mu \mathrm{m}$ and volume fraction of recrystallized grain was very high (above 0.70 ). Meanwhile, the outer side has larger grain size because recrystallization is not significant. The actual grain size is also compared with that of the simulated result. It can be seen that the predicted grain size matches well with experimental results made on the billet, indicating that the constitutive modeling successfully predicts the evolution of microstructure for cogging simulation. 


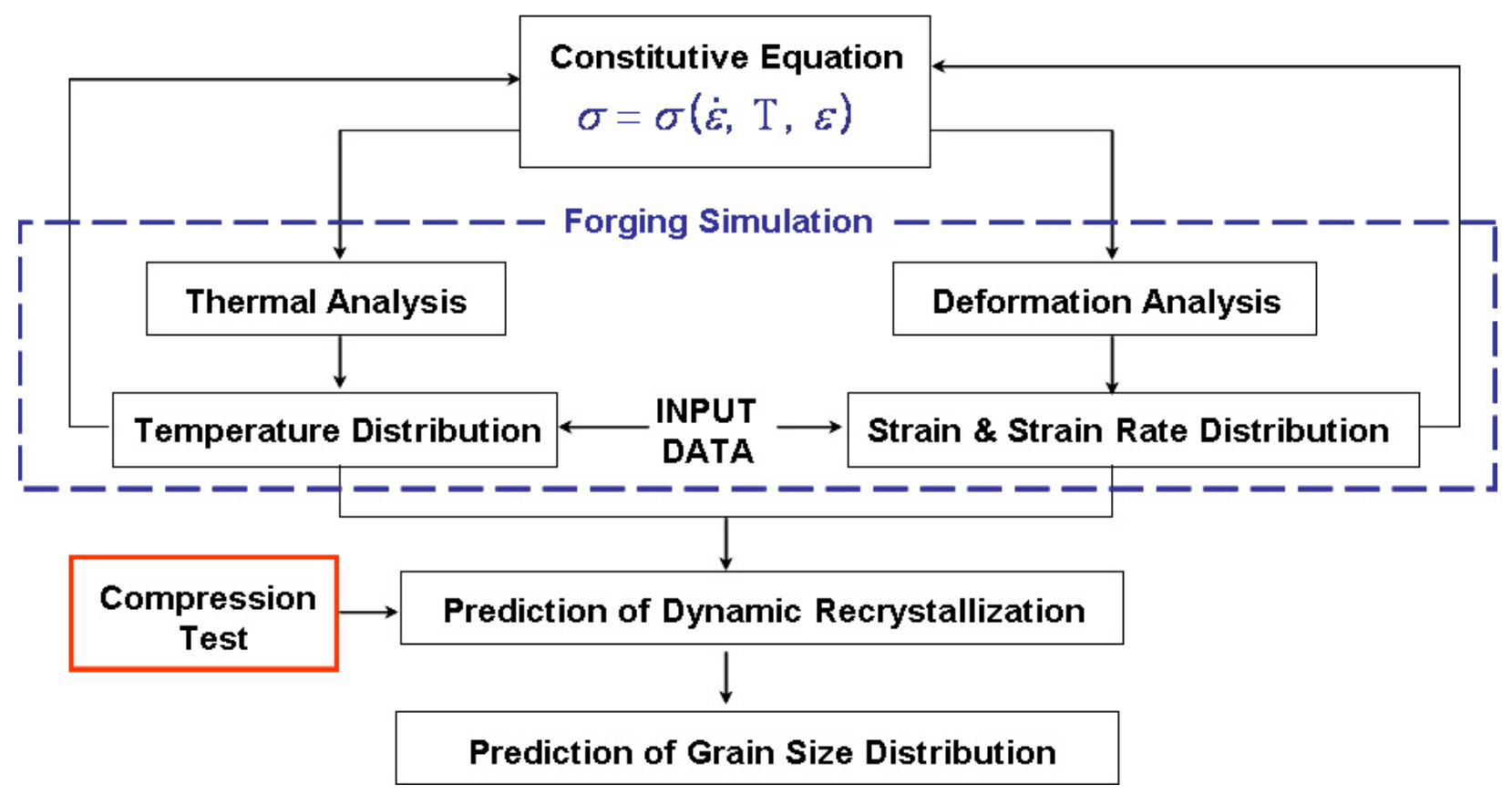

Fig. 8. Constitutive model-base simulation of grain size within the billet.

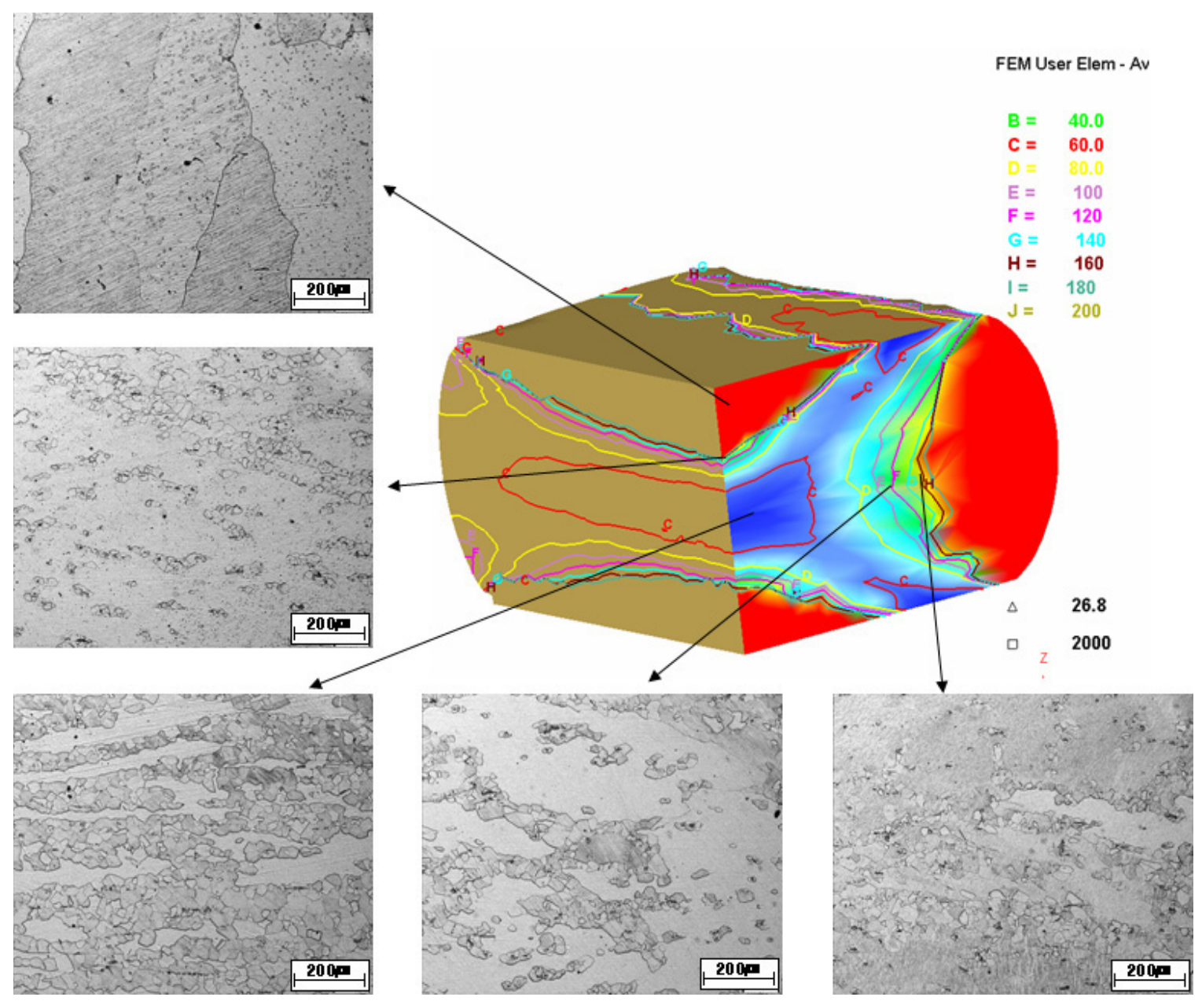

Fig. 9. Simulation results of the grain size match well with grain size distribution in the billet. 


\section{Conclusion}

The different grain zones of VIM/VAR-processed ingot with a diameter of $300 \mathrm{~mm}$ show a different flow behavior due to different solidification procedure during the ingot making process. Columnar grains show high flow stresses at normal cogging conditions, indicating that the crystal orientation in the columnar zone has 'hard' orientation compared to that of the central equiaxed grain zone. The difference in grain structure shows different flow behaviors, but disappears following the deformation at high temperatures, indicating the different microstructures follow a similar recrystallization route regardless of preferred orientations. Even with the orientation difference in casting structure, a large deformation in the billet cogging results in a similar recrystallization behavior and uniform microstructure in the end. The evolution of microstructure during cogging process was confirmed by decoupled FE simulation method, and the grain structure was well presented by the constitutive modeling based on the recrystallization and grain growth. The present methodology can be successfully used for the prediction of microstructure of Alloy 718 billet cogging process.

\section{Acknowledgement}

Present research is sponsored by MOCIE. Discussions on the metallographic work with Prof. H.K. Park of Korea Polytechnic University are appreciated.

\section{References}

[1] C.A. Dandre, S.M. Roberts, R.W. Evans, and R.C. Reed, Mat. Sci. Tech. 16 (2000), p.14.

[2] D. Zhao, S. Guillard, and A.T. Male, "High Temperature Deformation Behavior of Cast Alloy 718," Superalloy 718, 625, 706 and Various Derivatives, ed. E.A. Loria (Warrendale, PA: TMS, 1997), pp. 193-204.

[3] J. F. Radavich, "The Physical Metallurgy of Cast and Wrought Alloy 718," Superalloy 718 Metallurgy and Applications, ed. E.A. Loria (Warrendale, PA: TMS, 1989), pp. 229-240.

[4] R. M. F. Jones and L. A. Jackman, JOM 51(1) (1999), p.27.

[5] Y.S. Na, J.T. Yeom, N.K. Park and J.Y. Lee, Met. and Mater. Int 9(1) (2003), p15.

[6].Y.S. Na, J.T. Yeom, N.K. Park and J.Y. Lee, J. Mater. Proc. Technology, 141 (2003), p.337.

[7] N. K. Park, I. S. Kim, Y. S. Na, and J. T. Yeom, J. Mater. Proc. Technology, 111 (2001), p.98. 